Anna Achmatowicz-Otok, Monika Wagrowska

\title{
ATTEMPT AT APPLICATION OF THE GIS METHODS TO INVESTIGATION OF LANDSCAPE AESTHETICS PERCEPTION IN POLAND
}

\section{INTRODUCTION}

In the years 1986-1990 studies on perception, satisfaction and residential preferences of Poland's population were conducted under the research topic "Landscape aesthetics in social policy of the State". The investigations were coordinated by the Department of Social Geography and supervised by Dr Anna Achmatowicz-Otok. This paper presents the analysis of the results of studies on perception of aesthetics of this part of settlement landscape which is called the zone of comfort and safety in the place of residence.

\section{DEFINITIONS}

The investigations focus on landscape aesthetics of human settlements and their closest surroundings.

Landscape is an external expression and aspect of the natural environment. It is estimated and evaluated as a synthesis of integrated perceptions of diverse sights and the ensuing various feelings encoded in the observer's mind (Wojciechowski 1986).

The settlement landscape aesthetics is regarded as a reflection of social processes occurring in a given area, and as a result of the policy pursued by the State and its institutions with reference to the inhabitants (Achmatowicz-Otok 1990, pp. 159-182).

The term "zone of comfort and safety" has been used to denote the closest landscape zone: its boundary - apart from the buildings inside - is practically from several to some 200 hundred metres from the observer (Wojciechowski 1986, p. 283). Perception of stimuli received through the senses of sight, hearing and smell of the observer living in this zone is relatively strong and selective (Krzymowska-Kostrowicka 1991, p. 147). 


\section{METHODS}

Data on the perception were collected during the field investigation using questionnaires during one week in June 1990.

The method of the quota sampling was used. The magnitude of the sample was 1000 questionnaires, and the investigations were conducted throughout the country. The interviews were made in $\mathbf{4 3 6}$ localities situated in all parts of Poland. The number of the inverviews was in the quota proportion to the number of inhabitants of urban and rural areas, number of dwellers of the locality under investigation, their sex, age and education. The method of the quota sampling of adult population above 18 years of age comprises:

- in towns and settlements having the rank of a town - 324 females and 284 males,

- in rural areas - 199 females and 193 males.

Input and statistical analysis of the results of interviews was made using computer programmes OZIRYS and SPSS. The HARVARD GRAPHIC was used to draw the charts.

Using the statistical material obtained, the computer maps were prepared. The choice of programmes and computer operations in map making was made by Monika Wagrowska using the following programmes: ATLAS DRAW, ATLAS GRAPHIC AND SURFER. The ATLAS DRAW programme enabled the introduction of contours of Poland's boundaries as well as the marking of the localities in which interviews were conducted. The map obtained was written using the ATLAS GRAPHIC computer programme in the ASCI code which can be read by the SURFER programme. The analyzed part of results of the interviews was directly introduced into the SURFER programme under its sub-programme GRID, as the latter permits a simultaneous determination of interpolated values at nodes.

Interpolation was made twice: once - assuming the grid size of $200 \times 200$ (it was subsequently used to make a map of isolines), and secondly - assuming the grid size of $25 \times 25$ (which was then used to prepare a threedimensional map). The nodal values were determined using the method of kriging by selecting points for interpolation under the option normall. Reduction of nodal points to Poland's contour was obtained by use of the options modify/blank.

The maps of isolines were obtained under the sub-programme TOPO using the cutting of isoline of 0.5 point.

The spatial orthogonal (three-dimensional) map was prepared under the SURF programme, assuming that coordinates $\mathrm{x}$ and $\mathrm{y}$ are constant and that the coordinate $\mathrm{z}$ is equal to 0.25 of the real value, the rotation angle being $255^{\circ}$. 
The people interviewed were asked i.a. the following question: "Generally speaking, do you like your closest neighbourhood? What we mean is the assessment of what you see close to your place of residence, several up to 200 metres from your house."

The respondents had five possibilities of the answer: from definitely positive, through hesitation up to definitely negative. The analysis of answers to the above questions was conducted on a national scale.

Figure 1 shows that the prevalent carefully positive opinion $(46.7 \%$ respondents) is more frequent than the definitely positive one $(25.1 \%)$. Negative opinions are also more often hesitating (16.4\%) than unhesitating $(8.5 \%)$. All in all, positive perception (71.8\%) is more often encountered than the negative one $(24.9 \%)$, whereas the margin of hesitating respondents (3.3\%) was insignificant.

Characteristically, hesitating opinions ("rather yes" and "rather no") constitute a considerable percentage of the answers (63.1\%). This testifies to mixed impressions flowing from observation and perception of landscape aesthetics in the immediate vicinity of the respondent's house. Those people had both positive and negative feelings and perception, which made them choose the answers comprising the two possibilities of assessment at the

\section{DO YOU LIKE LANDSCAPE up to $200 \mathrm{~m}$ around the house}

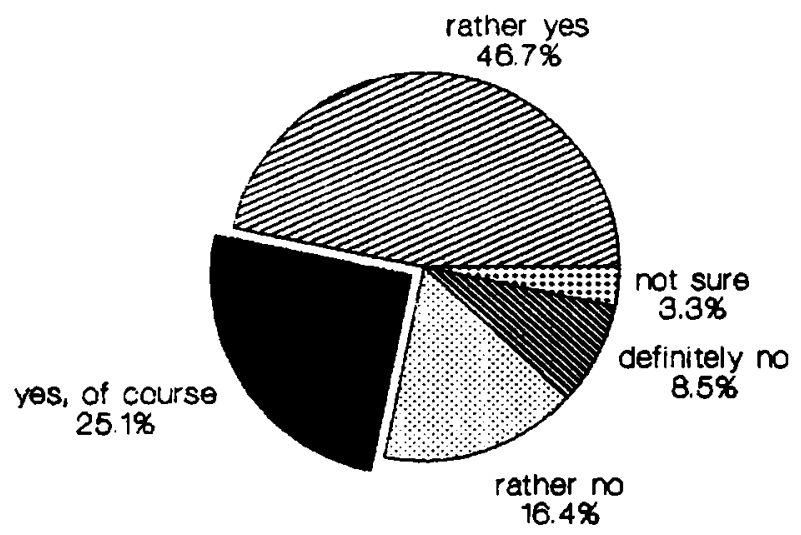

POLSKA 1990

Fig. 1. The total respondents 
same time, with a prevailing tendency towards the positive direction among some respondents ("rather yes" $46.7 \%$ ) or the negative direction among the others ("rather no" $16.4 \%$ ).

It should also be emphasized that almost $25 \%$ of the population oscillated towards the negative assessment, $8.5 \%$ expressing a definitely negative opinion about the aesthetics of the surrounding landscape.

The respondents' age plays an important role in perception of landscape in the place of residence (Fig.2). A definitely positive perception has been recorded chiefly among the population aged 61 and more ("definitely yes" $33.3 \%$ ). Definitely negative evaluation is expressed by the people aged 2130 years ("definitely no" $-9.6 \%$ ). In the group of those who hesitated ("not sure" $-5.2 \%$ ) the youths of up to 20 years of age are predominant.

The perception of landscape aesthetic surrounding the house in Poland is also related to the education level (Fig.3). In the group declaring definitely positive opinions ("definitely yes" $-30.2 \%$ ) there is a higher percentage of people having elementary education, while in the groups declaring carefully negative and definitely negative opinions there are more people with the university education ( $23 \%$ and $18 \%$ respectively).

The analysis of perception of landscape aesthetics of the zone of comfort and safety has revealed a considerable spatial differentiation.

The areas in which a definitely positive perception prevails are in the minority (Fig.4). They are concentrated in north-east Poland, in the Holy

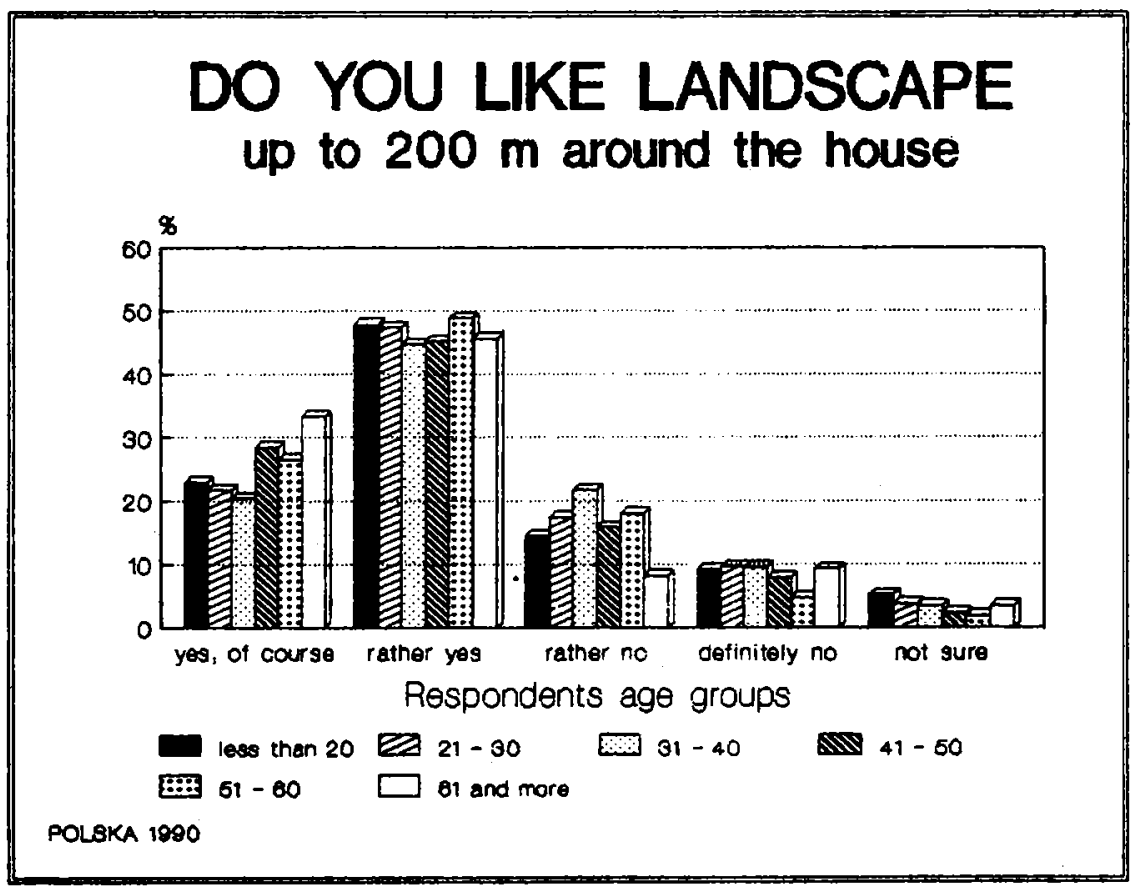

Fig. 2. Respondents by age groups 


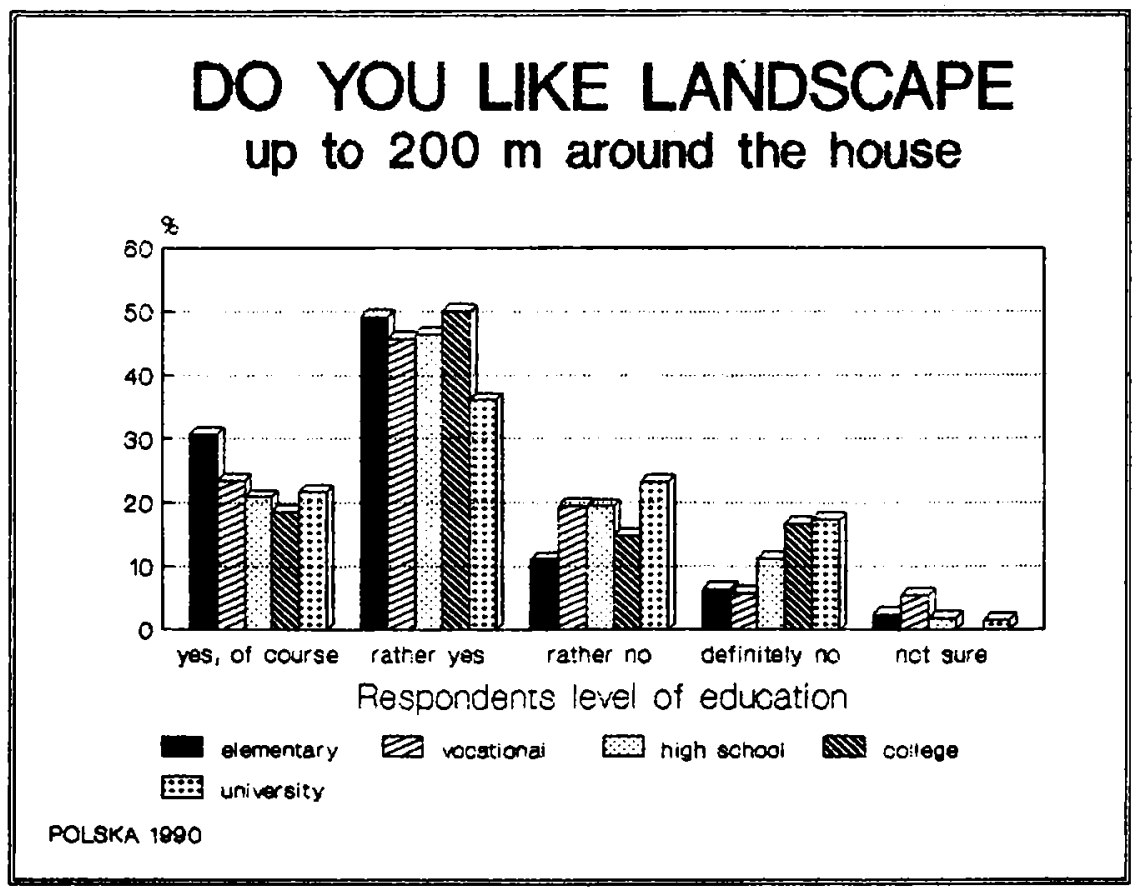

Fig. 3. Respondents by level of education

Cross Mts. as well as in small areas adjacent to the southern and southwestern border of the country.

The areas in which a carefully negative perception of landscape surrounding the place of residence has been recorded are prevalent all over the country (Fig.5).

There are not many areas in which carefully negative and negative perception prevails (Fig.6). The largest ones are found in central Poland (east of Warsaw), in the east - in the Biała Podlaska voivodship, in the north near Leba and Elblag, and in the south - in Upper Silesia and near Rzeszów. Prevalence of definitely negative perception has been recorded in the particular localities which do not constitute dense areas.

The synthetic map of isolines (Fig.7) shows a very complicated picture of spatial differentiation of landscape aesthetics perception in Poland. Although the map corroborates the investigations conducted previously which show that a considerable spatial differentiation of landscape aesthetics perception in Poland has been recorded on a country and town scale (Dutt, Achmatowicz-Otok Jr., Achmatowicz-Otok 1991, pp. 285-292), as well as on the scale of small localities inhabited by several dozen people (Noble, Achmatowicz-Otok 1990, pp. 227-232), the map of isolines represented in a twodimensional convention is difficult to read here. 


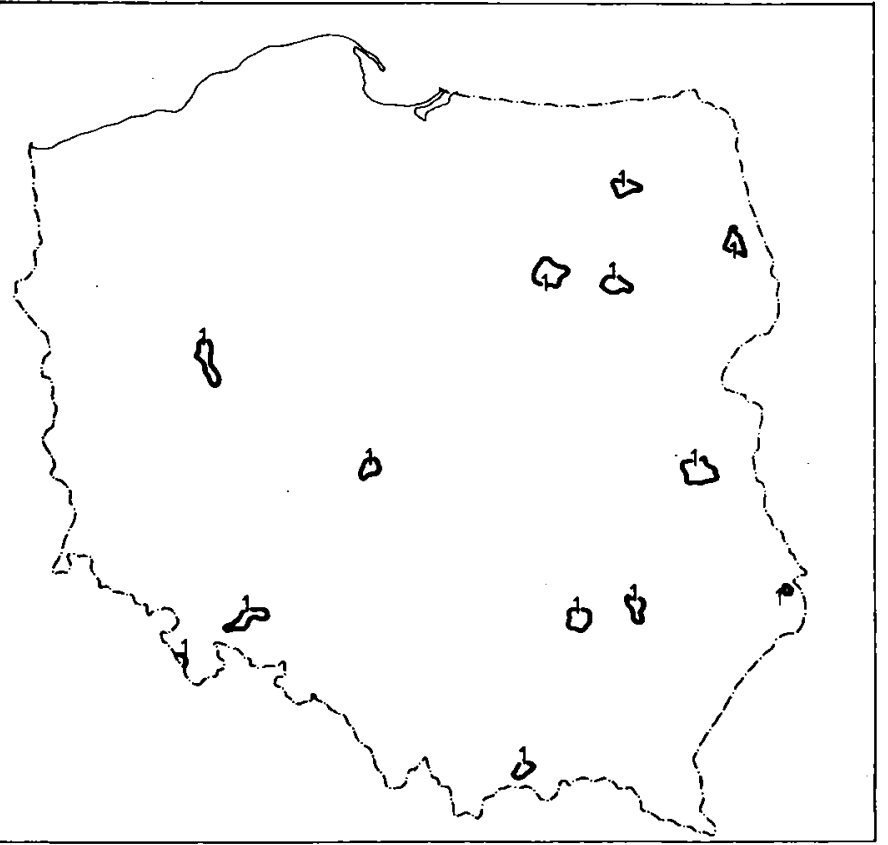

Fig. 4. Distribution of definitely positive perception of land-scape aesthetics

A more legible form of presentation of a complicated situation in the domain of landscape perception was obtained using a three-dimensional map (Fig.8). It represents the magnitude of negative perception of

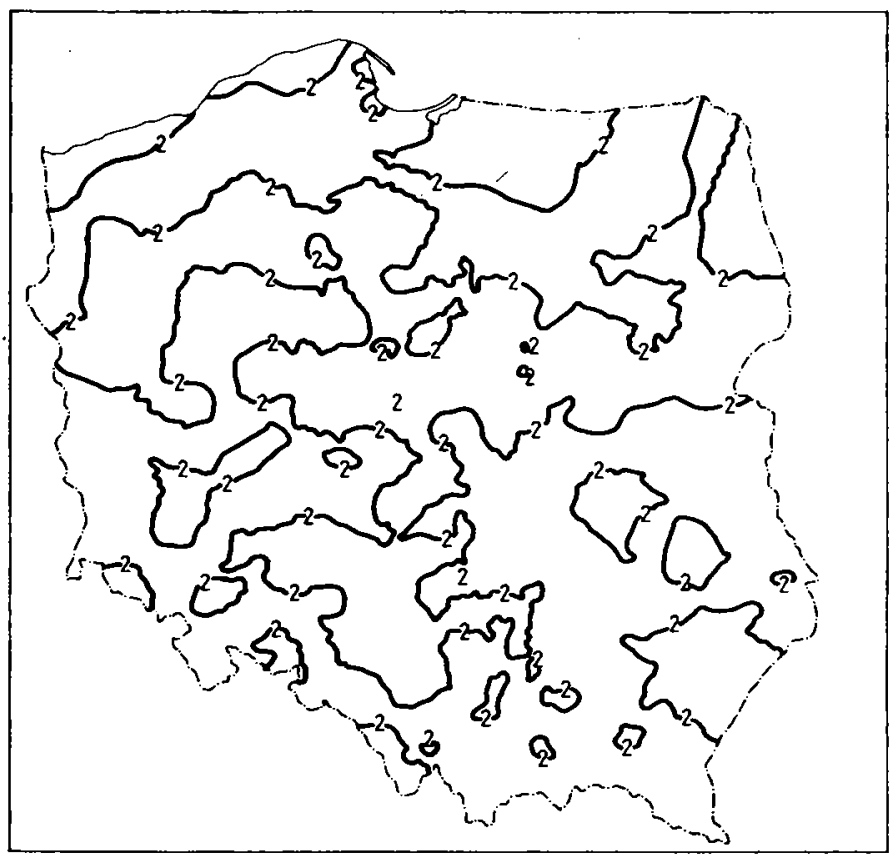

Fig. 5. Distribution of carefully positive perception of landscape aesthetics 


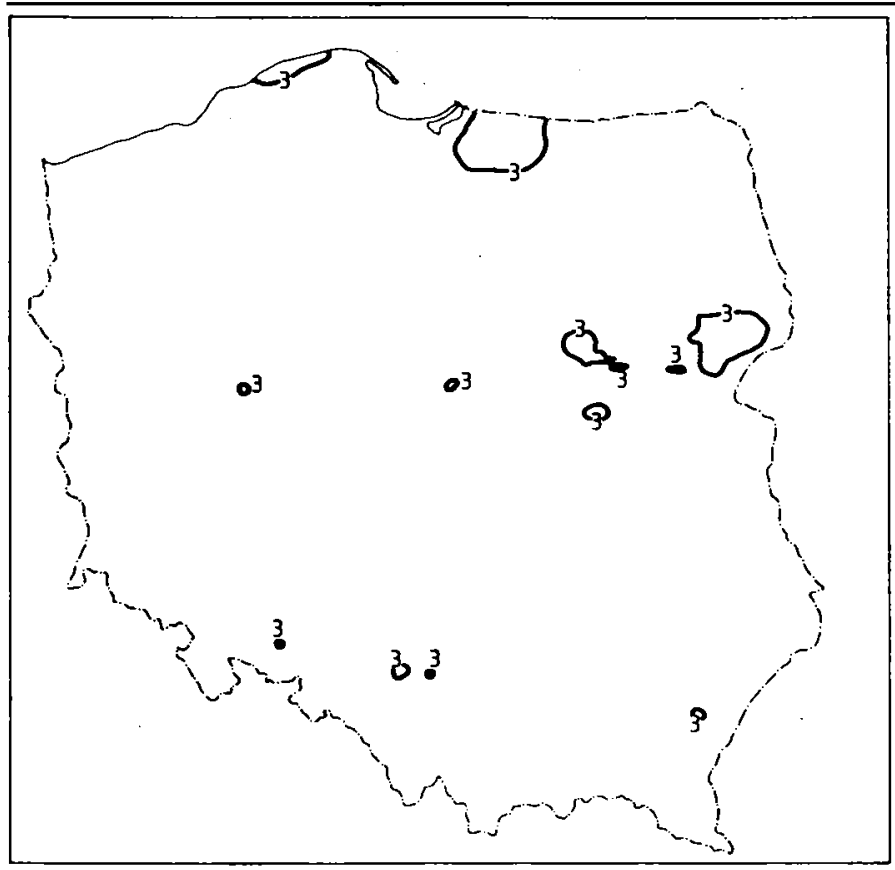

Fig. 6. Distribution of carefully negative perception of landscape aesthetics

landscape aesthetics occurring in direct vicinity of the Polish houses. The peaks indicate a definitely negative perception of landscape aesthetics among the inhabitants of the given area. The analysis of location of these

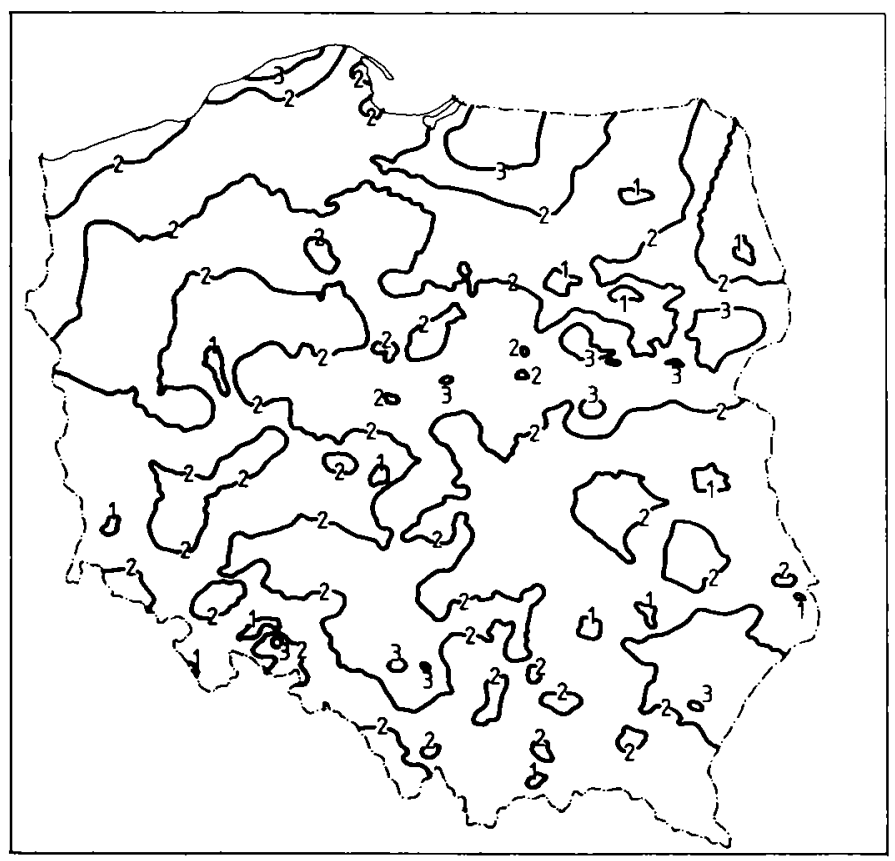

Fig. 7. Differentiation of perception of lands. cape aesthetics in Poland 


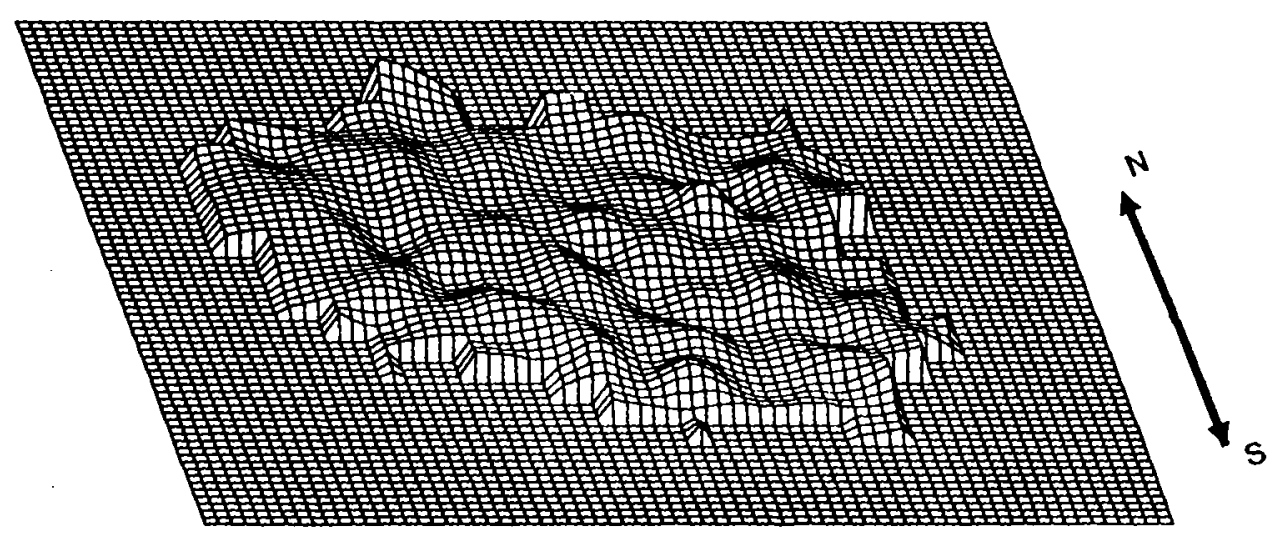

Fig. 8. Height of negative perception of landscape aesthetics in Poland

terrains also shows their clear-cut diversity. A definitely negative perception of landscape aesthetics of the place of residence has been observed among the population in areas degraded by industry (e.g. Upper Silesia) and by transport (e.g. Elblag, Tczew) as well as in traditional agricultural areas lying to the east of Warsaw (e.g. Wiązowna). In the latter, small private factories have been established in recent years, thus causing adverse changes in the natural environment as well as a peculiar cultural revolution in the social environment.

The GIS methods applied to the investigations on spatial differentiation of landscape perception have appeared to be very useful. As a result, a number of computer maps have been obtained. They show the extent of the phenomenon under investigation in the analyzed towns and localities, as well as estimates of perception in places where no direct interviews have been made.

\section{REFERENCES}

Achmat owicz-O tok A., 1990, "Estetyka krajobrazu w polityce społecznej państwa" (Landscape aesthetics in social policy of the state), in: Srodowisko naturalne $w$ polityce spotecznej panstwa (Natural Environment in Social Policy of the State), S.Otok (ed.), Warszawa.

Dutt A., Achmat owicz-Otok S. Jr., Achmatowicz-Otok A., 1991, "Residential preferences in the city of Warsaw, Poland," GeoJournal 24.3.

Krzy mow ska-Kostrowi ck a A., 1991, Zarys geoekologii rekreacji (Outline of Geoecology of Recreation), Uniwersytet Warszawski, Vol.1.

Noble A., Achmatowicz-Otok A., 1990, "Perception of Housing and community conditions in a suburban settlement of Warsaw, Poland" in: Applied Geography Conferences, (ed.) Frazier J. and others, Vol.13, Binghamton, New York.

Tánski T., 1991, Surfer, Wyd. PLJ, Warszawa.

Wojciechowski K.H., 1986, Problemy percepcji $i$ oceny estetycznej krajobrazu (Problems of Perception and Aesthetic Evaluation of Landscape), Wyd.UMCS. 